\title{
The concentration of conjugated linoleic acid isomers and their metabolites in the abdominal fat of rats
}

\author{
K. Korniluk, M. Czauderna ${ }^{1}$ and J. Kowalczyk \\ The Kielanowski Institute of Animal Physiology and Nutrition, \\ Polish Academy of Sciences \\ 05-110 Jabłonna, Poland
}

\begin{abstract}
The influence of adding Se-enriched yeast (Se-yeast) to a diet containing $2 \%$ of a mixture of conjugated linoleic acid isomers (CLAmix) on the profile of CLA isomers and their metabolites (CFA) in abdominal fat of rats was investigated. The results demonstrated that the concentration of CLA isomers and CFA was higher in the abdominal fat of rats fed the diet enriched in both Se-yeast and CLAmix compared with rats fed the diet supplemented only with the CLAmix.
\end{abstract}

KEY WORDS: CLA isomers, metabolites, abdominal fat, rats, selenized yeast

\section{INTRODUCTION}

Conjugated linoleic acid (CLA) isomers are present in the fat associated with meat and milk of ruminants (Wahle et al., 2004). Anticarcinogenic, antiatherosclerotic, antidiabetogenic, and antiadipogenic properties have been attributed to CLA isomers, particularly their longer chain metabolites (CFA), and to Se (Belury, 2002). It is likely that the physiological activities of CLA isomer metabolites may overlap with the properties of the parent CLA isomers. Se and CLA isomers also affect bone formation, the immune system, fatty acid and lipid metabolisms, and gene expression in numerous tissues (Banni et al., 2004; Suzuki, 2005). It has also been found that in rats, the concentration of polyunsaturated fatty acids positively correlated with the level of Se in diets (Czauderna et al., 2004). The main aim of this study was to evaluate the influence of a diet enriched in high-selenized yeast (Se) and/or mixture of CLA isomers on the profile of CLA isomers and their metabolites (CFA) in abdominal fat of rats. Silver-ion ( $\mathrm{Ag}^{+}$-HPLC), reversed-phase (RP-HPLC) high-performance liquid chromatography with photodiode array detection (DAD) and capillary gas-liquid chromatography (GLC) were adapted to analyse CLA isomers and CFA in rat fat.

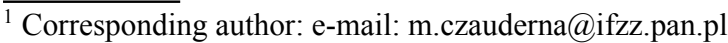




\section{MATERIAL AND METHODS}

Four groups of female rats (Wistar, Ifz: BOA), 8 weeks of age with an initial body weight of $\sim 200 \mathrm{~g}$, were housed individually as described previously (Korniluk et al., 2006). During a one-week preliminary period the rats were fed a standard Labofeed diet at a submaintenance level (daily $\sim 9 \mathrm{~g}$ of the diet per rat) to reduce their body fat. In the experimental period lasting 4 weeks, rats were fed ad libitum with the Labofeed diet enriched in $1.2 \mathrm{ppm}$ Se (as Se-yeast) and/or the CLA isomer mixture (CLAmix) at a level of 2\% (Table 1). At the end of the experimental period the rats were killed by $\mathrm{CO}_{2}$; abdominal fat samples were taken and analysed for CLA isomers and CFA concentration.

All of the reagents used, the methods of hydrolysis, derivatization and $\mathrm{Ag}^{+}-$ HPLC or GLC configuration were as previously described (Korniluk et al., 2006). The derivatized CLA isomers and CFA were determined by PR-HPLC (Czauderna et al., 2002), while non-derivatized fatty acids were analysed using $\mathrm{Ag}^{+}-\mathrm{HPLC}$ (Czauderna et al., 2003) and RP-HPLC (Czauderna et al., 2002). The CLAmix was supplied by Larodan Fine Chemicals AB (Sweden). Eighty-three per cent of the total Se content of selenized yeast (Se-yeast) represent Se in the form of Se-methionine incorporated into the proteins of Saccharomyces cerevisiae. Seenriched yeast was donated by Sel-Plex (Alltech Inc., USA).

Statistical analyses of the effects of Se-yeast on the concentration of CLA isomer(s) and CFA in fat were conducted using the nonparametric Mann-Whitney $\mathrm{U}$ test. Differences were considered significant at the $\mathrm{P}<0.05$ or $\mathrm{P}<0.01$ level.

\section{RESULTS AND DISCUSSION}

The concentrations of CLA isomers and their metabolites containing a pair of conjugated double bonds (CFA) was under the detection limit in rats fed the control and only Se-enriched diets (Table 1). No lesions or symptoms of Seyeast or CLA isomer intoxication were found in rats fed diets enriched in CLA isomers and/or Se-yeast. The diet enriched in Se-yeast, regardless of the presence of CLAmix, had a very small influence on the body weight gain of rats, while the dietary CLAmix tended to decrease the weight of rats (i.e. an antiobesity property of CLA isomers). As expected, both diets enriched in the CLAmix resulted in a significant increase in the concentration of CLA isomers in abdominal fat. Moreover, addition of Se-yeast to the diet with CLAmix elevated the accumulation of CLA isomers, particularly $c 9 t 11 \mathrm{CLA}$ and $c, c \mathrm{CLA}$, in the abdominal fat of rats compared with the group fed the diet with only CLAmix (Table 1). $\mathrm{Ag}^{+}-\mathrm{HPLC}$ investigations demonstrated that two unidentified non-CLA fatty acids (CFA) in abdominal fat have an absorbance maximum at $\sim 234 \mathrm{~nm}$ due to the presence of 
conjugated double bonds and had retention times of $18.3 \pm 0.2$ and $19.3 \pm 0.2 \mathrm{~min}$. Moreover, detailed RP-HPLC studies using direct DAD-detection of free fatty acids as well as DAD-monitoring after derivatization of fatty acids of abdominal fat demonstrated that the two unidentified non-CLA fatty acids contained a pair of conjugated double bonds and had an additional third non-conjugated bond. These fatty acids (CFA) contained three double bonds and twenty-carbon atoms in a chain because they eluted faster than CLA isomers, and slower than aracidonic acid. Thus, based on our earlier works (Czauderna et al., 2004; Korniluk et al., 2006), and studies of Banni et al. (2004), as well retention times of detected CFA and their UV spectra, we suggest that these fatty acids are higher metabolites such as $c 8 t 12 c 14 \mathrm{C} 20: 3$ and $c 8 c 11 t 13 \mathrm{C} 20: 3$. Based on current chromatographic analyses and our previous studies (Czauderna et al., 2004; Korniluk et al., 2006), we suggest that CLA isomers could be metabolized in vivo into long-chain conjugated PUFA (via $\Delta 6-, \Delta 5$-desaturation and elongation of CLA isomers) using the same pathway as linoleic acid (Czauderna et al., 2004). Our results demonstrate that the concentration of CFA is higher in the abdominal fat of rats fed the diet

Table 1. Mean concentrations of CLA isomer(s) $(\mu \mathrm{g} / \mathrm{g})^{1}$ in abdominal fat of rats fed a diet enriched to $1.2 \mathrm{ppm} \mathrm{Se}$ (as Se-yeast) and/or $2 \%$ of the CLA isomer mixture

\begin{tabular}{|c|c|c|c|c|c|c|c|c|}
\hline Group & $\begin{array}{l}\text { Body weight } \\
\text { gain }^{3}, \mathrm{~g}\end{array}$ & $\mathrm{n}$ & $\Sigma t, t^{2}$ & $t 10 c 12 C L A$ & $c 9 t 11$ CLA & $\Sigma c, c^{2}$ & CFA & $\begin{array}{c}\begin{array}{c}\text { Eall } \\
\text { isomers }\end{array} \\
\end{array}$ \\
\hline Control & 61.1 & 8 & $\mathrm{NQ}^{5}$ & NQ & NQ & NQ & NQ & NQ \\
\hline $\mathrm{Se}$ & 60.9 & 8 & NQ & NQ & NQ & NQ & NQ & NQ \\
\hline CLAmix $^{4}$ & 56.4 & 7 & NQ & 4125 & 6172 & $2914^{a}$ & $18665^{\mathrm{a}}$ & $31875^{\mathrm{a}}$ \\
\hline $\mathrm{CLAmix}+\mathrm{Se}$ & 60.4 & 8 & 95 & 5051 & 7748 & $13508^{\mathrm{a}}$ & $33737^{\mathrm{a}}$ & $60141^{\mathrm{a}}$ \\
\hline
\end{tabular}

${ }^{1}$ means in columns with the same letter are significantly different at a,b $\mathrm{P}<0.05 ;{ }^{2} t, t$ - trans,trans CLA isomers; $c, c$ - cis, cis CLA isomers; $\Sigma$ - all isomers - sum of all CLA isomers and CFA (metabolites of CLA isomers); ${ }^{3}$ the weight gain of rats after 4 weeks feeding with experimental diets; ${ }^{4}$ the profile of CLA isomer mixture: $0.06 \%$ - the sum of $t 11 t 13, t 10 t 12, t 9 t 11$ and $t 8 t 10 ; c 10 t 12-49.2 \% ; c 9 t 11-48.0 \%$; $1.026 \%$ - the sum of $c 11 c 13, c 10, c 12, c 9 c 11$ and $c 8 c 10 ;{ }^{5} \mathrm{NQ}$ : below the quantification limit $\left(\mathrm{L}_{\mathrm{Q}}\right)$

enriched in Se-yeast and CLAmix compared with rats fed the diet with only CLAmix (Table 1). The present data are consistent with our previous results showing that dietary selenate stimulates the formation of higher metabolites in femoral muscles and liver of rats fed diets with CLA isomers (Czauderna et al., 2004). These results clearly indicate that dietary $t, t$ CLA isomers are discriminately accumulated into abdominal fat, in contrast with being preferentially incorporated into phospholipids and triacylglycerols of rat liver (Czauderna et al., 2004). In agreement with our previous studies, addition of Se-yeast to the diet with CLAmix slightly increased the accumulation of $t, t$ isomers in fat.

The concentration ratio of $c 9 t 11 \mathrm{CLA}$ to $110 \mathrm{c} 12 \mathrm{CLA}$ in fat of rats fed the diets enriched in CLAmix with or without Se-yeast was higher compared with the 
concentration ratio of these isomers in CLAmix added to the diets (i.e. $1.49-1.53$ vs 0.98; Table 1). These results are in agreement with our previous studies (Czauderna et al., 2004; Korniluk et al., 2006) and with that of Belury (2002), in which $110 c 12$ CLA and $t 10 t 12$ CLA were also driven through $\beta$-oxidation in rat adipose cells, muscles, kidneys and liver more efficiently than their 9,11 homologues.

\section{CONCLUSIONS}

We hypothesize that dietary Se-yeast decreases the catabolism of CLA isomers as well as stimulates the capacity of $\Delta 6$ desaturase and elongase in rats. Finding that the addition of Se-enriched yeast to a diet enriched in CLAmix increased the concentration of CLA isomers and, in particular, of their higher metabolites (CFA) in fat is valuable information for nutritionists trying improve the nutritive value of food.

\section{REFERENCES}

Banni S., Petroni A., Blasevich M., Carta G., Angioni E., Murru E., Day B.W., Melis M.P., 2004. Detection of conjugated C16 PUFAs in rat tissues as possible partial beta-oxidation products of naturally occurring CLA and its metabolites. Biochim. Biophys. Acta 1682, 120-127

Belury M.A., 2002. Dietary conjugated linoleic acid in health: physiological effects and mechanism of action. Annu. Rev. Nutr. 22, 505-531

Czauderna M., Kowalczyk J., Korniluk K., Wąsowska I., 2005. Improving the analysis of fatty acids using combination of gas chromatography and $\mathrm{Ag}^{+}$-liquid chromatography. J. Anim. Feed Sci. 14, Suppl. 1, 563-566

Czauderna M., Kowalczyk J., Niedźwiedzka K.M., Wąsowska I., Pastuszewska B., Bulska E., Ruszczyńska A., 2004. Liver and body mass gain, content of CLA isomers and other fatty acids in the liver of rats fed CLA isomers and selenium. J. Anim. Feed Sci. 13, 353-369

Czauderna M., Kowalczyk J., Potkański A., Szumacher-Strabel M., 2002. Determination of conjugated fatty acid in ovine milk, meat, fat and intestinal digesta. Ars Separat. Acta 1, 104-110

Czauderna M., Kowalczyk J., Wąsowska I., Niedźwiedzka K.M., 2003. Determination of conjugated linoleic acid isomers by liquid chromatography and photodiode array detection. J. Anim. Feed Sci. 12, 369-382

Korniluk K., Czauderna M., Kowalczyk J., Mieczkowska A., Taciak M., Leng L'., 2006. Influence of dietary conjugated linoleic acid isomers and selenium on growth, feed efficiency, and liver fatty acid profile in rats. J. Anim. Feed Sci. 15, 131-146

Suzuki K.T., 2005. Metabolomics of selenium: Se metabolites based on speciation studies. J. Health Sci. 51, 107-114

Wahle K.W.J., Heys S.D., Rotondo D., 2004. Conjugated linoleic acids: are they beneficial or detrimental to health? Prog. Lipid Res. 43, 553-587 